\title{
Cellular Redox Imbalance and Neurochemical Effect in Cognitive-Deficient Old Rats
}

\author{
Maria Elena González-Fraguela ${ }^{1, *}$, Lisette Blanco-Lezcano ${ }^{2}$, \\ Caridad Ivette Fernandez-Verdecia ${ }^{2} \mathbb{( D}$, Teresa Serrano Sanchez ${ }^{1}{ }^{1}$, \\ Maria de los A. Robinson Agramonte ${ }^{1}$ and Lidia Leonor Cardellá Rosales ${ }^{3}$ \\ 1 Immunochemical Department, International Center for Neurological Restoration, 25th Ave, Playa, 15805, PC \\ 11300 Havana, Cuba; teresa@neuro.ciren.cu (T.S.S.); robin@neuro.ciren.cu (M.d.1.A.R.A.) \\ 2 Experimental Neurophysiology Department, International Center of Neurological Restoration (CIREN) Ave. \\ 25 No. 15805 e/158 and 160, Playa, Havana 11300, Cuba; lblanco@neuro.ciren.cu (L.B.-L.); \\ ivettef@neuro.ciren.cu (C.I.F.-V.) \\ 3 Physiologic Sciences Department, Latin American Medicine School, Carretera Panamericana, Kilómetro 3 \\ 1/2 Municipio Playa, Habana 19148, Cuba; lcardella@infomed.sld.cu \\ * Correspondence: marie@neuro.ciren.cu; Tel.: +53-7-2715353
}

Received: 22 August 2018; Accepted: 8 October 2018; Published: 13 October 2018

\begin{abstract}
The purpose of the present study is to access the linkage between dysregulation of glutamatergic neurotransmission, oxidative metabolism, and serine signaling in age-related cognitive decline. In this work, we evaluated the effect of natural aging in rats on the cognitive abilities for hippocampal-dependent tasks. Oxidative metabolism indicators are glutathione (GSH), malondialdehyde (MDA) concentrations, and cytosolic phospholipase $\mathrm{A}_{2}\left(\mathrm{PLA}_{2}\right)$ activity. In addition, neurotransmitter amino acid (L-Glutamic acid, $\gamma$-aminobutyric acid (GABA), DL-Serine and $D L$-Aspartic acid) concentrations were studied in brain areas such as the frontal cortex (FC) and hippocampus (HPC). The spatial long-term memory revealed significant differences among experimental groups: the aged rats showed an increase in escape latency to the platform associated with a reduction of crossings and spent less time on the target quadrant than young rats. Glutathione levels decreased for analyzed brain areas linked with a significant increase in MDA concentrations and $\mathrm{PLA}_{2}$ activity in cognitive-deficient old rats. We found glutamate levels only increased in the HPC, whereas a reduced level of serine was found in both regions of interest in cognitive-deficient old rats. We demonstrated that age-related changes in redox metabolism contributed with alterations in synaptic signaling and cognitive impairment.
\end{abstract}

Keywords: aging; learning; memory; neurotransmitter; oxidative stress; phospholipase $\mathrm{A}_{2}$; serine

\section{Introduction}

The demographic changes that affect a large part of humanity are leading to an increase in life expectancy at birth, which has a high impact on societies and their economies. The increase in health costs are not at the expense of the new generation, in fact they are very reduced, but at the expense of the predominance of pathologies related to aging and other physical and intellectual disabilities associated with advanced age.

Aging is an essential factor for many diseases, specifically in neurodegenerative diseases. Oxidative stress constitutes the most important theory of ageing at the molecular level. The cognitive processes that are mediated by the hippocampus (declarative memory) and the prefrontal cortex (working memory) represent the most vulnerable areas to ageing. 
This is due to brain cells that are exposed to rising levels of oxidative stress with the loss of energy homeostasis, and the increase in lipid mediators by phospholipases $\mathrm{A}_{2}\left(\mathrm{PLA}_{2}\right)$ activity, alterations in neurotransmitters, and signal transduction and accumulation of damage in biomolecules [1].

Oxidative stress is characterized by an imbalance in reactive oxygen species production (ROS) or impaired antioxidant protection. Both mechanisms are considered to have an important role in age-related cognitive decline. Glutathione (GSH) is the main mechanism of antioxidant defense against ROS in biological systems [2]. Glutathione concentration decreases with age in several animal models [3-5] and brain areas [6,7]. The reduction in GSH concentration causes an incomplete oxidation of the substrates into the mitochondria inducing the leakage of electrons from the electron transport chain and consequently increasing ROS generation.

A habitual target of ROS are neural membrane lipids, the enhanced phospholipid degradation induces changes in fluidity and permeability in neural membranes with the consequent alteration of ionic channels and modulation in the enzymatic activities coupled to membrane composition [8].

Previous studies have demonstrated the involvement of oxidative signaling pathways in a permanent damage of the neuronal circuitry, especially with glutamatergic neurons. Sustained activation of ionotropic glutamate receptors as the $N$-methyl-D-aspartic acid receptor (NMDAR), could affect intracellular calcium levels leading to activation of proteases, nucleases, and phospholipases [9].

The cytosolic PLA 2 causes the release of arachidonic acid (AA), hydrolyzing the sn-2 fatty acids of membrane phospholipids. This important polyunsaturated fatty acid (PUFA) is the precursor for the synthesis of eicosanoids and prostanoids. Some findings indicate that $\mathrm{PLA}_{2}$ plays important roles in synaptic functions, long-term potentiation (LTP), learning, and memory [10]. The effect of PLA 2 on cognitive function can be related with the ability of AA to change neuronal metabolism and synaptic activity [11].

Glutamate, an excitatory neurotransmitter in the central nervous system (CNS), plays a recognized role in the regulation of neurogenesis, neuronal survival, synaptic plasticity, and learning and memory processes [12].

Several studies have suggested that the stimulation of $\mathrm{PLA}_{2}$ is a process mediated by the glutamate receptor in neuronal cultures [10]. Likewise, D-serine is the most effective co-agonist of the glycine site of NMDAR, which is essential for the optimal function of this receptor in physiological and pathological processes [13].

Experimental data has demonstrated that D-serine treatment decreases the extent of neuron death with a neuroprotective effect against apoptosis [14]. At the present time, serine metabolism is the subject of intense investigation to confirm its role in the diagnosis and therapy of neurological disorders, as well as its therapeutic potential in preclinical models $[15,16]$.

The objective of this study was to obtain evidence about the linkage between dysregulation of glutamatergic neurotransmission in oxidative stress conditions and the role of serine signaling in age-related cognitive decline.

\section{Materials and Methods}

\subsection{Animal}

Male Sprague-Dawley rats obtained from a national breeder institution (CENPALAB, Artemisa) were housed five per cage in a 12:12-h light-dark cycle with food and water ad libitum, under standard conditions for temperature $\left(25^{\circ} \mathrm{C}\right)$ and relative humidity $(60 \%)$. All experimental studies were performed during light cycle (7.00-19.00 h). We used two age groups: young, $(n=30 ; 2$ months old) with a body weight $272 \pm 36 \mathrm{~g}$ (mean \pm standard deviation, SD); and cognitive-deficient old rats ( $n=45 ; 23$ months old, body weight $520 \pm 46 \mathrm{~g}$ ). 
All efforts were made to minimize the number of animals used and their suffering. All procedures concerning animal experimentation were carried out according to the ethical principles for animal research established by the Canadian Council for Animal Care [17] and the Cuban Regulations for the Use of Laboratory Animals (CENPALAB 1997) and were approved by the Ethical Committee of the International Center for Neurological Restoration.

\subsection{Behavioral Test}

\section{Morris Water Maze (MWM)}

The MWM tests spatial learning and memory retention in rodents and involves an acquisition phase where the animal learns the location of a "goal or escape platform" target over a period of multiple days [18]. An overhead camera and computer assisted tracking system with videomax software (Spontaneous Motor Activity Recording Tracking SMART 2.0) (PanLab, Barcelona España, Spain) was used to record the position of the rat in the maze (Scheme 1). A cued learning test was used to discriminate motoric or motivational factors. On the first day, animals received four trials in a water maze (no distal cues) with a well visible and distinguished platform located at different quadrants.

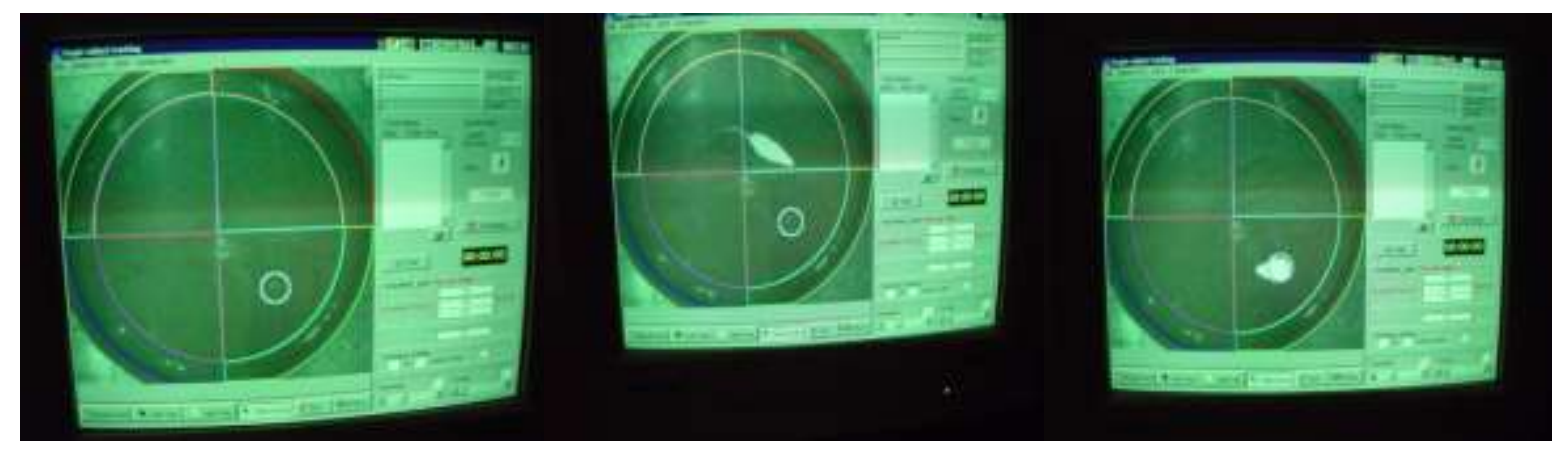

Scheme 1. The software display during data acquisition in the Morris water maze (MWM) task using the Spontaneous Motor Activity Recording Tracking (SMART) system from Panlab S.A.

One day after, a classic spatial acquisition test was introduced. Animals were trained in the MWM with non-visible platform conditions for eight trials per day over four consecutive days. The order of the start position was changed in every trial as well as the sequence of positions along the days. The platform position was kept fixed in the northeast position (NE target quadrant, Q1) throughout the training period (Scheme 2). In each trial, the rat was released from the starting position, facing the wall, and was allowed to search for a hidden escape platform for $60 \mathrm{~s}$. If the animal was unable to find the platform it was gently carried onto it, and allowed a $30 \mathrm{~s}$ rest period sitting on the platform. Data from each four trials were grouped into one block (4 days: 32 trials: 8 blocks-B1-B8). On the fifth day (trial 33), the platform was removed and the animal was allowed to search for it for $60 \mathrm{~s}$ (probe trial for Q1). This trial evaluated the quality of reference memory. Immediately, the platform was relocated in the same position (Q1) to evaluate four additional trials (34-37, B9) to explore the cognitive flexibility with a previous dissociating stimulus (absence of escape platform). Two days later, the rat's long-term reference memory was evaluated in a single block of four trials (B10) using the above described paradigm (Q1 at NE position).

Aged rats are classified according to the criteria of 2 or 2.5 standard deviations above the average of the young controls latency [19-21]. 


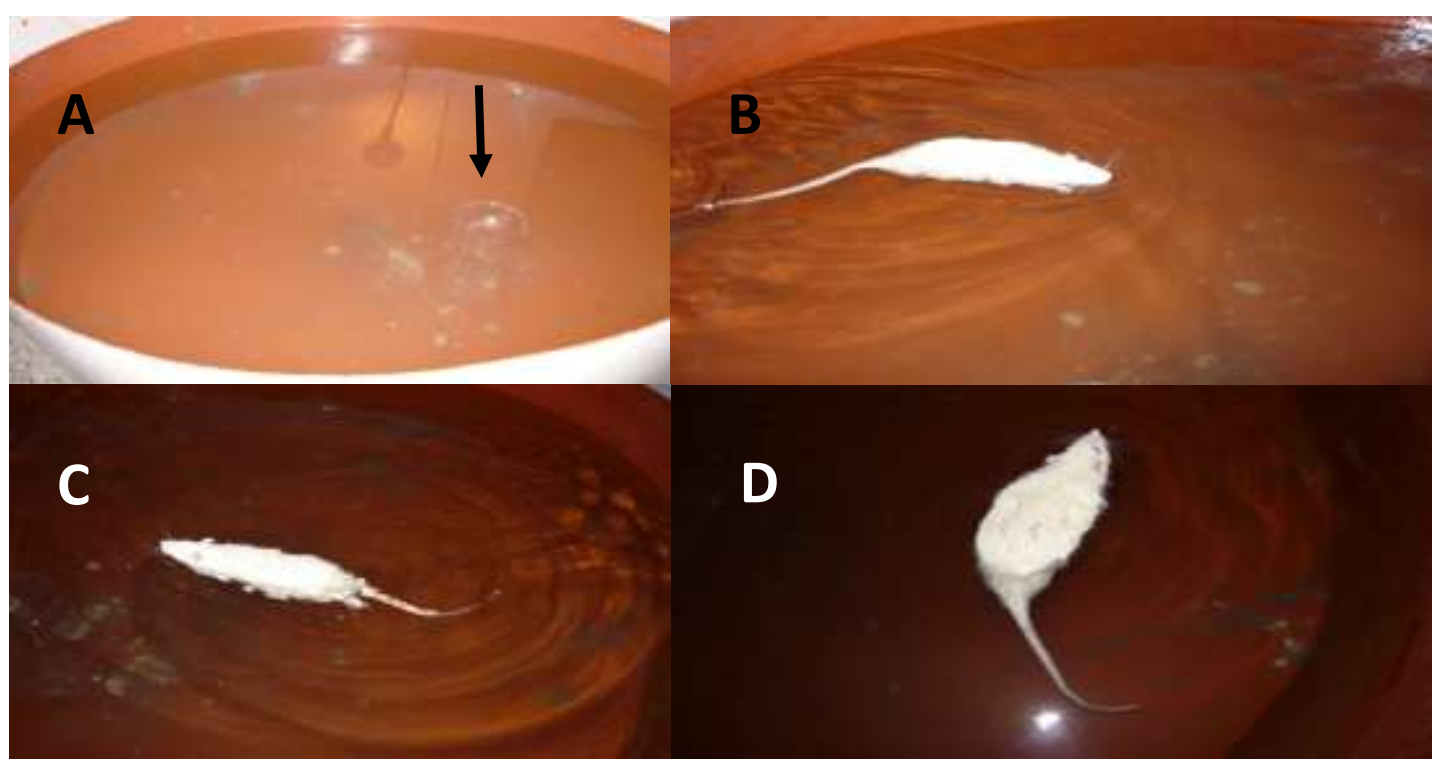

Scheme 2. (A) The tank before the task. The arrow shows the location of the platform. (B-D) The different moments in which the rat is searching for the platform in the maze and reaching it.

\subsection{Sedation and Sample Collection}

For the studies that required sedation, an anesthetic mixture of $4 \mathrm{~mL}$ of ketalar (ketamine $50 \mathrm{mg} / \mathrm{mL}$, IMEFA, Havana, Cuba), $2 \mathrm{~mL}$ of valium (diazepam $5 \mathrm{mg} / \mathrm{mL}$, IMEFA, Havana, Cuba), $1 \mathrm{~mL}$ of atropine (atropine, $0.5 \mathrm{mg} / \mathrm{mL}$, IMEFA, Havana, Cuba), and $16 \mathrm{~mL}$ of $0.9 \%$ sodium chloride solution $(0.9 \% \mathrm{NaCl}$, IMEFA, Havana, Cuba) was used. The dose regimen was $1 \mathrm{~mL}$ of the mixture $/ 100 \mathrm{~g}$ of body weight, and immediately the rats were sacrificed by decapitation. Their brains were extracted and rinsed in cold saline; the total frontal cortex (FC) and hippocampus (HPC) were bilaterally dissected. The tissues were frozen in liquid nitrogen, weighed, and stored at $-80^{\circ} \mathrm{C}$ until the biochemical analysis.

\subsection{Biochemical Analysis}

\subsubsection{Oxidative Stress Markers}

\section{Glutathione GSH Quantification}

Tissue samples were homogenized in a glass-Teflon potter containing 5\% 5-sulfosalicylic acid $(1: 15, w / v)$ and the protein-free supernatant was isolated by centrifugation at $8160 \times g$ during $10 \mathrm{~min}$. Total GSH was quantified by Tietze's recycling assay as described by Azbill et al. [22]. Aliquots of the supernatants were incubated for $25 \mathrm{~min}$ at $37{ }^{\circ} \mathrm{C}$ in a medium containing $0.21 \mathrm{mM} \mathrm{NADPH}$, $0.6 \mathrm{mM}$ DTNB (5,5'-ditiobis(2-nitrobenzoico), $6.3 \mathrm{mM}$ EDTA (ethylene diamine tetraacetic acid), and $143 \mathrm{mM}$ sodium phosphate $\mathrm{pH}$ 7.5. Following the addition of $0.5 \mathrm{U}$ GRD (glutathione reductasa), the absorbance increase at $412 \mathrm{~nm}$ due to the formation of 5-thio-nitrobenzoate was recorded. The concentration values were calculated from a GSH standard curve.

\section{Malondialdehyde (MDA) Quantification}

Tissues samples were homogenized in $1 \mathrm{M}$ Tris/0.25 M sucrose buffer ( $\mathrm{pH} 7.4$ ) at a tissue/buffer volume ratio of $1 / 5$. The homogenates were centrifuged at $14,000 \mathrm{rpm}$ for $15 \mathrm{~min}$. Two-hundred microliters of the sample were vortexed with $400 \mu \mathrm{L}$ of a $0.67 \%$ thiobarbituric acid solution in $0.2 \mathrm{M}$ $\mathrm{HCl}$, then incubated for $15 \mathrm{~min}$ in a water bath at $100{ }^{\circ} \mathrm{C}$ and centrifuged at $2448 \times g$ for $10 \mathrm{~min}$ at room temperature. The resulting supernatant was used for measuring absorbance at $535 \mathrm{~nm}$. The concentration values were calculated from an MDA standard curve [23]. 
Assay for Calcium-Dependent Cytosolic Phospholipase A2 (PLA2) Activity

$\mathrm{PLA}_{2}$ enzymatic activity was measured using the protocol recommended by the manufacturer (Cayman Chemical Company, Ann Arbor, MI, USA). Briefly, $10 \mu \mathrm{L}$ sample were incubated with $1.5 \mathrm{mM}$ arachidonoyl thio-phosphotidylcholine (a PLA $\mathrm{PL}_{2}$ substrate) for $1 \mathrm{~h}$ at room temperature. Enzyme catalysis was stopped by the addition of beta dystrobrevin/EGTA (Ethylene glycol-bis(2-aminoethylether)- $N, N, N^{\prime}, N^{\prime}$-tetraacetic acid), and the optical density of the sample was measured at $405 \mathrm{~nm}$. PLA 2 activity was calculated in accordance to kit instruction and PLA 2 activity was expressed in $\mathrm{U} / \mathrm{mg}$ [24].

\subsubsection{Amino Acid Analysis}

\section{Sample Preparation and Derivatization}

The brain tissue for amino acid analysis was homogenized in ice-cold $0.2 \mathrm{M}$ perchloric acid including cysteine ( $4 \mathrm{~mL}$ per $\mathrm{g}$ of tissue) and sonicated for $5 \mathrm{~min}$. The brain homogenate was centrifuged at $17,000 \mathrm{rpm}$ for $4 \mathrm{~min}$ at $4{ }^{\circ} \mathrm{C}$ and the supernatant was diluted (1/50), aliquoted, and stored at $-20^{\circ} \mathrm{C} .20 \mu \mathrm{L}$ of standard (L-Glutamic acid, $\gamma$-aminobutyric acid (GABA), DL-Serine and DL-Aspartate) or sample was added with $20 \mu \mathrm{L}$ of the derivatization reagent ( $25 \mathrm{mg}$ OPA (Ophthaldialdehyde) of diluted in $1500 \mu \mathrm{L}$ of methanol, $100 \mu \mathrm{L}$ of borate buffer $0.1 \mathrm{M}$ (pH9), and $30 \mu \mathrm{L}$ of $\beta$-mercaptoethanol), the derivatization mixture was vortexed for $1 \mathrm{~min}$ at room temperature, After that, $5 \mu \mathrm{L}$ of $5 \%$ acetic acid were added to stop of reaction, then, $20 \mu \mathrm{L}$ of this final solution was injected into the HPLC system.

Instrumentation and Chromatographic Conditions

For chromatographic analysis, an HPLC system (Agilent 1200 Technologies) (Santa Clara, CA, USA) was used. Chromatographic separation was achieved on a reversed phase column (HR-80, ESA), using an isocratic chromatographic pump (Agilent 1200 series), and detected with a fluorescence detector (Agilent G1321A, 1100 series) set at $\lambda_{\text {excitation }} 340 \mathrm{~nm}$ and $\lambda_{\text {emission }} 460 \mathrm{~nm}$. The column temperature was maintained at $25^{\circ} \mathrm{C}$ and the mobile phase was pumped at a flow rate of $1.0 \mathrm{mLmin}^{-1}$. The chromatographic data were recorded using the Agilent ChemStation B.04.02SP1 software. The mobile phase was composed of $0.1 \mathrm{M} \mathrm{NaH}_{2} \mathrm{PO}_{4} / 25 \%$ methanol.

\subsection{Data Processing and Statistical Analysis}

The values were expressed as mean \pm standard error mean. Normal distribution and homogeneity of variance of the data were tested by the Kolmogorov-Smirnov and Levene tests, respectively. The comparison between experimental groups of the biochemical indicators was performed by a one-way analysis of variance (ANOVA) and the behavioral variables in the MWM were analyzed by analysis of variance for repeated measurements (ANOVA). For post hoc comparisons was used the Tukey honest significant differences test (HSD) and nonparametric comparison with Mann-Whitney U test. Significant differences were considered only if $p<0.05$.

\section{Results}

\subsection{Behavioural Studies}

Morris Water Maze

The post-hoc analysis on spatial long-term memory revealed significant differences between experimental groups for escape latency to platform $\left(\mathrm{F}_{(1,28)}=12.39 ; p<0.001\right)$ related with an increase in aged rats that demonstrated severe spatial memory impairment in this group (Figure 1). Likewise, regarding the number of crossings, the aged rats exhibited a poor performance in the acquisition of the navigation search strategy during the test. The Tukey honest significance differences test, showed a 
reduction of crossings and time spent on the target quadrant in older animals than younger rats $\left(\mathrm{F}_{(1,28)}\right.$ $=8.91 ; p<0.001)($ Figure 2, Table 1).

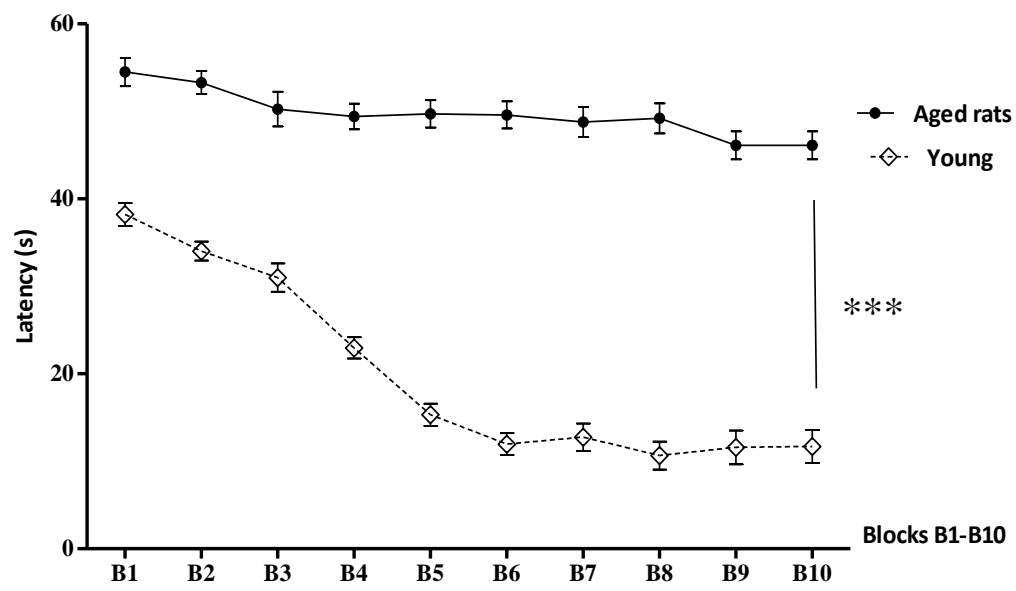

Figure 1. Latency in the MWM (mean $\pm S D$ mean are represented) to find the hidden platform during the training sessions grouped into the blocks (B). Classical training (B1-B9) and long-term contextual memory (B10). ${ }^{* * *}$ Significant differences between experimental groups: aged rats $(n=45)$ and young $(n=30)(p<0.001)$.

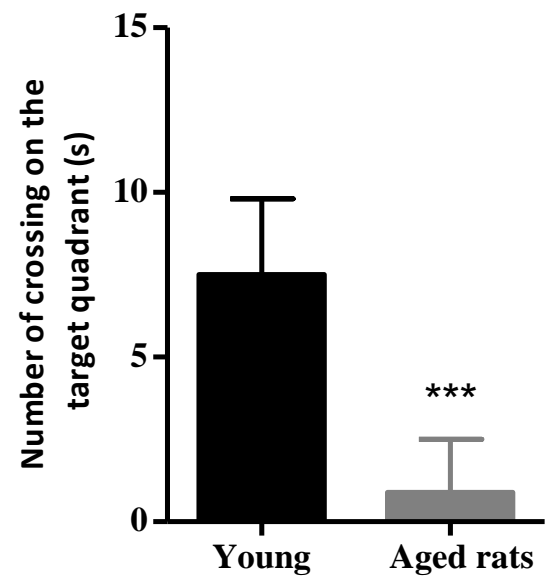

Figure 2. Number of crossings on the target quadrant (mean \pm SD mean are represented) ${ }^{* * *}$ Significant differences between experimental groups: aged rats $(n=45)$ and young $(n=30)(p<0.001)$.

Table 1. Data (mean \pm SD mean) from four trials grouped in blocks (B1-B10) for the latency in the MWM and the number of crossings in the target quadrant between experimental groups.

\begin{tabular}{ccc}
\hline Blocks (B) & Aged Rats (Mean \pm SD Mean) & Young (Mean \pm SD Mean) \\
\hline B1 & $54.5 \pm 1.62$ & $38.20 \pm 1.32$ \\
B2 & $53.30 \pm 1.33$ & $34.02 \pm 1.087$ \\
B3 & $50.26 \pm 1.97$ & $30.99 \pm 1.61$ \\
B4 & $49.41 \pm 1.48$ & $22.96 \pm 1.20$ \\
B5 & $49.7 \pm 1.56$ & $15.30 \pm 1.27$ \\
B6 & $49.59 \pm 1.54$ & $11.96 \pm 1.26$ \\
B7 & $48.8 \pm 1.70$ & $12.75 \pm 1.57$ \\
B8 & $48.2 \pm 1.73$ & $10.66 \pm 1.59$ \\
B9 & $46.12 \pm 1.60$ & $11.58 \pm 1.94$ \\
B10 & $46.06 \pm 1.7$ & $11.70 \pm 1.92$ \\
Number of Crossings & $0.9 \pm 1.6$ & $7.5 \pm 2.3$ \\
\hline
\end{tabular}




\subsection{Biochemical Indicators}

The comparison between experimental groups with regard to GSH content showed significant differences in examined brain areas in cognitive-deficient old rats $\left(\mathrm{FC}(\mathrm{Z}=5.41 ; p<0.001) ; \mathrm{HPC}\left(\mathrm{F}_{(1,38)}\right.\right.$ $=288.6 ; p<0.001)$ ). The level of GSH dropped by $82 \%$ in FC and $80 \%$ in HPC in respect to the control groups. These results are associated with a significant increase in MDA concentrations for aged rats only for hippocampus, a highly sensitive region to oxidative stress. $\left(\operatorname{HPC}\left(\mathrm{F}_{(1,38)}=837.9 ; p<0.001\right)\right)$.

Similarly, a considerable increase was observed in $\mathrm{PLA}_{2}$ activity for analyzed brain areas. The enzyme activity revealed significant differences among experimental groups $\left(\mathrm{FC}\left(\mathrm{F}_{(1,38)}=29.15 ; p<\right.\right.$ 0.001); $\left.\operatorname{HPC}\left(\mathrm{F}_{(1,38)}=70.96, p<0.001\right)\right)$ in correspondence with the reduction of GSH content in the studied brain structures GSH: Glutathione, MDA: Malondialdehyde, PLA2: Phospholipase $\mathrm{A}_{2}, \mathrm{GABA}$ : $\gamma$-aminobutyric acid. (Figure 3, Table 2).
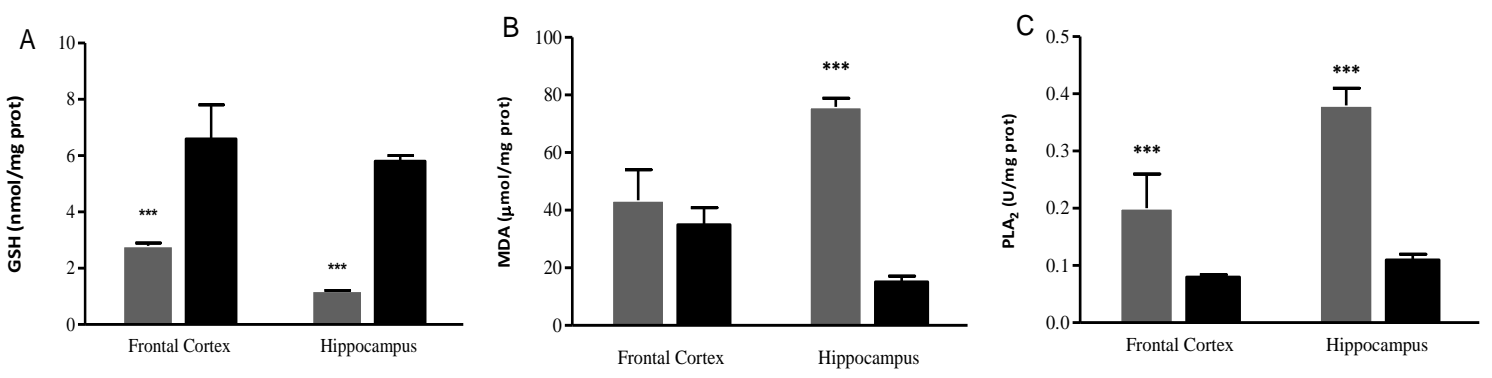

Aged rats
Young

Figure 3. Effect of aging on oxidative metabolism indicators in the examined brain areas. (A) Glutathione (GSH), (B) Malondialdehyde (MDA), (C) Phospholipase A2 (PLA2). ** Corresponds to significant differences between experimental groups $(p<0.001)$.

Table 2. Data (mean \pm SD mean) corresponding to biochemical indicators in examined brain areas between experimental groups.

\begin{tabular}{ccccc}
\hline $\begin{array}{c}\text { Biochemical } \\
\text { Indicators }\end{array}$ & $\begin{array}{c}\text { Frontal Cortex } \\
\text { Aged Rats }\end{array}$ & $\begin{array}{c}\text { Frontal Cortex } \\
\text { Young Rats }\end{array}$ & $\begin{array}{c}\text { Hippocampus } \\
\text { Aged Rats }\end{array}$ & $\begin{array}{c}\text { Hippocampus } \\
\text { Young Rats }\end{array}$ \\
\hline GSH & $1.3 \pm 0.1$ & $5.45 \pm 1.2$ & $0.76 \pm 0.22$ & $5.15 \pm 0.2$ \\
MDA & $43.42 \pm 10.6$ & $34.93 \pm 5.95$ & $80.31 \pm 3.01$ & $15.84 \pm 2.02$ \\
PLA 2 & $0.2 \pm 0.06$ & $0.08 \pm 0.0$ & $0.35 \pm 0.03$ & $0.11 \pm 0.01$ \\
L Glutamate & $5.29 \pm 0.8$ & $5.17 \pm 1.10$ & $10.24 \pm 1.2$ & $6.89 \pm 1.2$ \\
GABA & $0.88 \pm 0.03$ & $0.94 \pm 0.02$ & $1.11 \pm 0.03$ & $1.17 \pm 0.03$ \\
DL Serine & $4.85 \pm 0.8$ & $6.07 \pm 0.55$ & $2.13 \pm 1.02$ & $5.52 \pm 1.2$ \\
DL Aspartate & $5.35 \pm 0.72$ & $5.4 \pm 0.55$ & $5.02 \pm 1.03$ & $5.16 \pm 1.2$ \\
\hline
\end{tabular}

\section{Amino Acid Concentrations}

The levels of GABA were unchanged compared with controls in brain regions investigated in aged rats $\left(\mathrm{FC}\left(\mathrm{F}_{(1,38)}=0.17 ; p>0.05\right)\right.$ and $\left.\operatorname{HPC}\left(\mathrm{F}_{(1,38)}=0.39 ; p>0.05\right)\right)$. Furthermore, the aspartate concentrations were not significantly different between groups $\left(\mathrm{FC}\left(\mathrm{F}_{(1,38)}=0.18 ; p>0.05\right)\right.$ and $\mathrm{HPC}$ $\left.\left(\mathrm{F}_{(1,38)}=0.70 ; p>0.05\right)\right)$. In contrast, the levels of glutamate only increased in HPC in aged rats (HPC $\left(\mathrm{F}_{(1,38)}=93.32 ; p<0.001\right)$, whereas a reduced level of serine was found in the regions of interest in cognitive-deficient old rats $\left(\mathrm{FC}\left(\mathrm{F}_{(1,38)}=58.3 ; p<0.001\right)\right.$ and $\left.\operatorname{HPC}\left(\mathrm{F}_{(1,38)}=365.1 ; p<0.001\right)\right)$ (Figure 4, Table 2). 

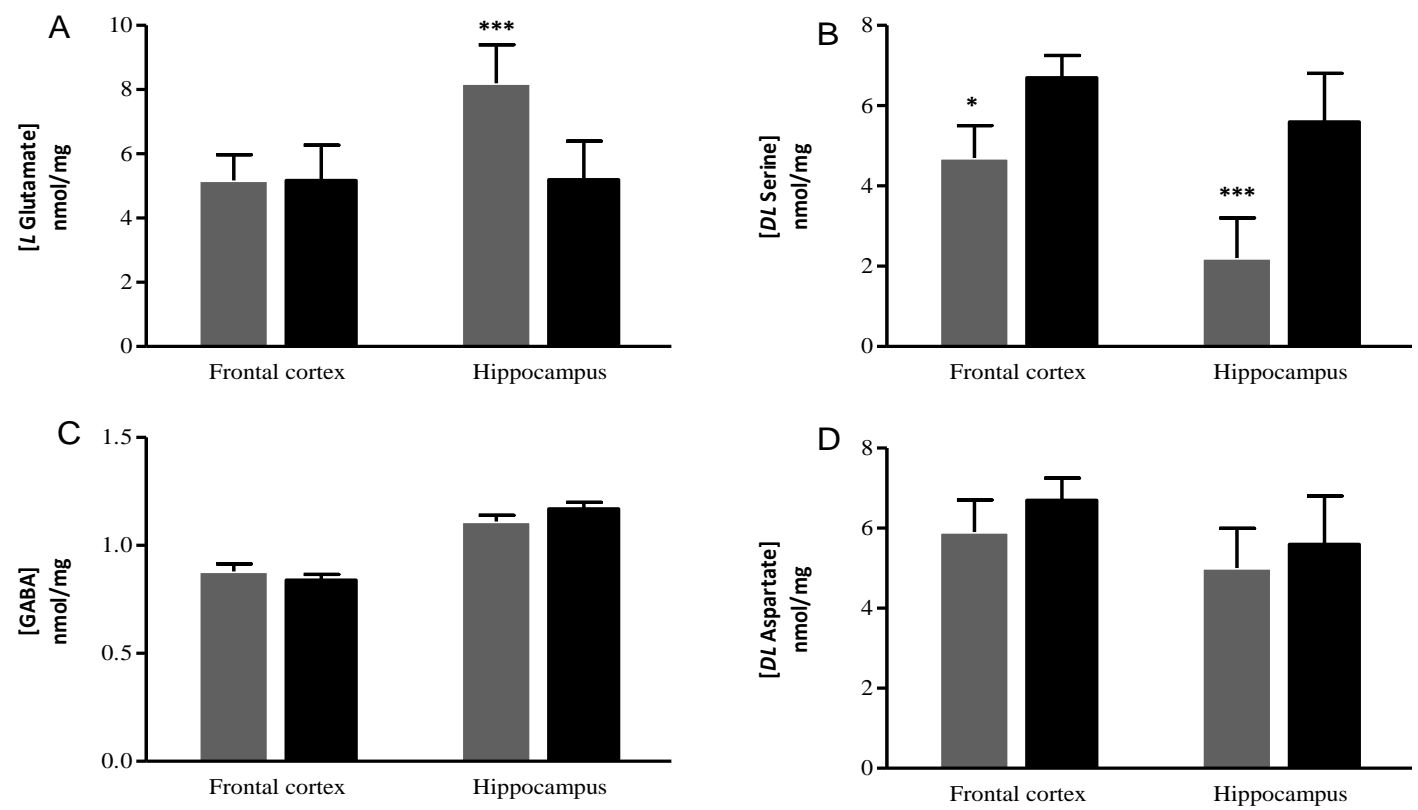

Aged rats

Figure 4. Effect of aging on amino acid concentration in the examined brain areas. (A) $L$ Glutamate, (B) DL Serine, (C) GABA, (D) DL Aspartate. ${ }^{* * *}(p<0.001) ; *(p<0.05)$ corresponds to significant differences between experimental groups.

\section{Discussion}

Some aged animals undergo severe cognitive deficiencies, whereas others preserve their normal cognitive abilities. In particular, spatial memory appears to be significantly affected [25]. The behavioral results allowed us to select aged rats that demonstrated a deficient execution in the acquisition of a successful navigation strategy in the MWM. The metabolic changes originated by GSH depletion in HPC caused increased swim times in the MWM test associated with a reduction of time spent on the target quadrant, confirming a failure in the memory trace formation, and therefore cognitive dysfunction.

We observed a significant GSH depletion in cognitive-deficient old rats, as much in FC as in HPC. Besides its roles in maintenance of oxidant homeostasis within the cell, GSH may serve as a substrate and an allosteric modulator of eicosanoid biosynthesis, in the regulation of NMDAR activity and activation of transcription factors [26]. We found a reduction of more than $70 \%$ in the GSH content in cognitive-deficient old rats compared to the young rats. The majority of authors have reported a decreases of tripeptide in brain tissue of around $50 \%$ in previous rodent studies [27,28].

The strong GSH decrease observed in our work generates hydrogen peroxide $\left(\mathrm{H}_{2} \mathrm{O}_{2}\right)$ and hydroxyl radical $(\mathrm{OH})$ that induce lipid peroxidation in the membrane of neurons and glial cells and damage the $\left(\mathrm{Ca}^{2+}\right.$ and $\left.\mathrm{Na}^{+} / \mathrm{K}^{+}\right)$ATPases and glucose transporters [29]. In connection with this result, we observed a significant increase in MDA concentration and PLA 2 activity in aged rats for examined brain areas. The loss of the energy metabolism homeostasis, redox imbalance, and subsequent damage by accumulation of MDA could originate the functional impairment in aged rats.

Due to its numerous functions for maintenance of membrane phospholipid balance and for originating several lipid mediators, $\mathrm{PLA}_{2}$ activation has been implicated in pathological conditions in the CNS for neurodegenerative diseases among others [8,30-32].

$\mathrm{H}_{2} \mathrm{O}_{2}$ accumulation induces the redox ambience appropriate for activating the PLA $\mathrm{A}_{2}$ pathway by means of extracellular signal-regulated kinase (ERK) and interleukin $1 \mathrm{~b}[33,34]$. In this context, $\mathrm{PLA}_{2}$ activity increases the release of AA from the plasma membrane, which directly produce 4-hydroxynonenal and MDA. 
Arachidonic acid AA undergoes oxidative modifications and increases the mitochondrial ROS levels in the hippocampus and cerebral cortex [35]. As such, the AA and its metabolites are permeable to the membrane and could affect the function of neighboring neurons with disruption of monolayer integrity and cell death [36].

The results obtained from the cognitive-deficient old rats revealed high PLA $A_{2}$ enzymatic activity and consequently increased AA generation. It is important to point out that high concentrations of AA cause uncoupling oxidative phosphorylation with a detrimental effect on the ATP-producing capacity of mitochondria, which results in mitochondrial dysfunction and an additional increase in the production of ROS.

These experimental data are in line with clinical studies. Jiang $R$ et al. [37] reported that higher $\mathrm{PLA}_{2}$ enzymatic activity is associated with increased prevalence of cognitive impairment in the Chinese population. On the other hand, there is evidence that the contribution of $\mathrm{PLA}_{2}$ activity in regulating neuronal excitatory functions, in cultured primary cortical neurons, trigger NMDAR receptors, which has been demonstrated to activate $\mathrm{PLA}_{2}$ and AA release [38]. In turn, $\mathrm{PLA}_{2}$ activity and AA are involved in receptor signaling which is linked with oxidative events which underline important roles in synaptic signaling, LTP, learning and memory [39,40].

In consonance with these studies, the present findings evidence an increase in glutamate concentrations in the HPC of aged rats which is closely associated with the elevation of PLA 2 activity in this region. The LTP dependence of NMDAR activation has been demonstrated in several brain areas, including hippocampal subfields like the dentate gyrus and the CA1 [41].

It is well established now that excessive levels of glutamate can produce toxic effects due to overstimulation of NMDAR, increasing the intracellular $\mathrm{Ca}^{2+}$ and activate $\mathrm{Ca}^{2+}$-dependent enzymes including $\mathrm{PLA}_{2}$. This cascade of events culminates with a $\mathrm{Ca}^{2+}$ dysregulation in neurons and astrocytes, which initiates cellular death by a process known as excitotoxicity. This process implicates the activation of proteases, the generation of radical species, and mitochondrial $\mathrm{Ca}^{2+}$ overload that affects critical biological molecules including lipids, proteins, and DNA.

However, on the other hand, one of the deleterious consequences of GSH metabolism dysfunction is the NMDAR hypoactivity [42]. The GSH insufficiency in aged rats could induce the formation of disulfide bonds between pairs of cysteine residues on the extracellular portion of the NMDAR generating a selective reduction of NMDAR currents [42], which contrast with the possible excitotoxic effect of NMDAR activation in old rats due to high levels of glutamate.

Previous studies with NMDAR blockade suggested that altered redox states of these extracellular cysteine residues could mediate the decline in NMDAR function during aging [43]. The application of dithiothreitol, a specific reducing agent, increased the NMDAR component and the magnitude of LTP in hippocampal slices from old rodents [43].

The intracellular redox status observed in the aged rats can directly contribute to synaptic inefficiency of NMDAR, caused by changes in neurotransmitter systems in vulnerable brain regions. Liu et al. [44] have reported that $\mathrm{H}_{2} \mathrm{O}_{2}$ accumulation is associated with the downregulation of the GluN2 subunits of the NMDAR in adult rat hippocampi. Otherwise, recent modeling work has shown that reduced NMDAR signaling into interneurons produced alterations in spatial representations that affected working memory execution [45]. Therefore, the suppression of NMDAR responses could induce changes in memory mechanisms that impaired the cognitive processes in GSH-depleted aged rats.

This previous hypothesis is supported by a reduced level of serine in the brain regions investigated in aged rats. D-serine, an enantiomer of serine, has a crucial characteristic of binding to NMDAR [46]. This amino acid binds to the glycine-site of the GluN1 subunit of NMDAR so that glutamate can link to GluN2 subunits [47].

We found a reduction of around 60\% in serine levels in HPC and 30\% in FC in cognitive-deficient old rats with regard to younger counterparts. The bond of D-serine is critical to synaptic NMDAR function [48] due to D-serine having three additional hydrogen bonds to the receptor, which may 
activate the NMDAR more efficiently than glycine [49]. This finding increases the possibility that alterations in serine metabolism could be a contributor to the dysfunctions of memory in the aged rats.

$\mathrm{D}$-serine is converted from L-serine by serine racemase, an enzyme dependent of pyridoxal phosphate, mostly expressed in excitatory neurons in the CNS of rodents [50]. D-serine is especially increased in brain areas involved in cognitive processes, as in the cerebral cortex, hippocampus, and basal ganglia [49].

The pathway responsible for the degradation of D-serine in the CNS is the D-amino acid oxidase (DAAO) [51]. Nevertheless, the reduction in serine concentration could involve an exceptional property of serine racemase which is able to catalyze the degradation of D-serine and L-serine to pyruvate and ammonia [13].

The possibility of serine racemase to enhance pyruvate levels from metabolic availability of serine may represent an important mechanism to obtain energy for mitochondrial oxidative phosphorylation and synthesis of ATP. This alternative of the serine metabolic pathway explains how the increased ROS production secondary to GSH depletion observed in aged rats reduces the synaptic levels of D-serine and exacerbates the NMDAR dysfunction in increased energy demand conditions.

These results are coincidental with reports from others authors who have shown that alterations of LTP expression are associated with a deficiency of NMDAR [52-54] and is recovered in aged rats and senescence-accelerated mice by D-serine treatment [54].

\section{Conclusions}

These findings suggest that age-related changes in the cellular redox metabolism contributes to memory dysfunctions and cognitive decline. The energy demands of synaptic activity lead to increased ROS production as a by-product of ATP synthesis with elevated utilization of a glutathione-based antioxidant system. Glutathione depletion induces an acute increase in the oxidative stress conditions and may generate NMDAR hypofunction and alterations in synaptic transmission. In the same way, the reduction of serine levels in aged rats, as the most effective co-agonist, could lead to a marked impairment of NMDAR function. The results discussed here support the hypothesis of redox homeostasis as a crucial element that regulates brain function and it will be necessary to further research the molecular mechanism of observed results.

Author Contributions: This work was carried out in collaboration between all authors. M.E.G.-F. was the principal investigator, designed the study, conducted the data analysis and wrote of the paper. L.B.-L. and C.I.F.-V. supervised the statistical analysis and assisted with interpreting the results and revision of the manuscript. T.S.S. and M.d.l.A.R.A. participated in the analysis of the data. L.L.C.R. participated in the analysis of the data and revision of the manuscript. All authors read and approved the final manuscript.

Funding: This study was supported financially by the CIREN Scientific Council.

Conflicts of Interest: The authors declare no conflict of interest.

\section{References}

1. Zhang, Y.; Li, P.; Feng, J.; Minghu, W. Dysfunction of NMDA receptors in Alzheimer's disease. Neurol. Sci. 2016, 37, 1039-1047. [CrossRef] [PubMed]

2. Mari, M.; Morales, A.; Colell, A.; Garcia-Ruiz, C.; Fernandez-Checa, J. Mitochondrial Glutathione, a Key Survival Antioxidant. ARS 2009, 11, 2685-2700. [CrossRef] [PubMed]

3. Bergado, J.A.; Almaguer, W.; Rojas, J.; Capdevila, V.; Frey, J.U. Spatial and emotional memory in aged rats: A behavioral-statistical analysis. Neuroscience 2011, 172, 256-269. [CrossRef] [PubMed]

4. Krämer, T.; Grob, T.; Menzel, L.; Hirnet, T.; Griemert, E.; Radyushkin, K.; Thal, S.C.; Methner, A.; Schaefer, M.K.E. Dimethyl fumarate treatment after traumatic brain injury prevents depletion of antioxidative brain glutathione and confers neuroprotection. J. Neurochem. 2017, 143 (Suppl. 5), 523-533. [CrossRef] [PubMed] 
5. Gemelli, T.; de Andrade, R.B.; Rojas, D.B.; Zanatta, Â.; Schirmbeck, G.H.; Funchal, C.; Wajner, M.; Dutra-Filho, C.S.; Wannmacher, C.M.D. Chronic Exposure to $\beta$-Alanine Generates Oxidative Stress and Alters Energy Metabolism in Cerebral Cortex and Cerebellum of Wistar Rats. Mol. Neurobiol. 2018, 55 (Suppl. 6), 5101-5110. [CrossRef] [PubMed]

6. Cruz-Aguado, R.; Almaguer-Melian, W.; Diaz, C.M.; Lorigados, L.; Bergado, J. Behavioral and biochemical effects of glutathione depletion in the rat brain. Brain Res. Bull. 2001, 55 (Suppl. 3), 327-333. [CrossRef]

7. Bonasera, S.; Arikkath, J.; Boska, M.D.; Chaudoin, T.R.; De Korver, N.W.; Goulding, E.H.; Traci, A.; Hoke, T.A.; Mojtahedzedah, V.; Reyelts, C.D.; et al. Age-related changes in cerebellar and hypothalamic function accompany non-microglial immune gene expression, altered synapse organization, and excitatory amino acid neurotransmission deficits. Aging 2016, 8, 2153-2164. [CrossRef] [PubMed]

8. Chauhan, V.; Chauhan, A. Abnormalities in membrane lipids, membrane-associated proteins, and signal transduction in Autism. In Austim Oxidative Stress, Inflammation and Immune Abnormalities; Chauhan, A., Ed.; CRC Press: Boca Raton, FL, USA, 2010; pp. 177-207.

9. Paoletti, P.; Bellone, C.; Zhou, Q. NMDA receptor subunit diversity: Impact on receptor properties, synaptic plasticity and disease. Nat. Neurosci. 2013, 14, 383-400. [CrossRef] [PubMed]

10. Basselin, M.; Chang, L.; Chen, M.; Bell, J.M.; Rapoport, S. Chronic Administration of Valproic Acid Reduces Brain NMDA Signaling via Arachidonic Acid in Unanesthetized Rats. Neurochem. Res. 2008, 33, 2229-2240. [CrossRef] [PubMed]

11. Ng, C.Y.; Kannan, S.; Chen, Y.J.; Tan, F.C.; Ong, W.Y.; Go, M.L.; Verma, C.S.; Low, C.M.; Lam, Y. A New Generation of Arachidonic Acid Analogues as Potential Neurological Agent Targeting Cytosolic Phospholipase A2. Sci. Rep. 2017, 7, 13683. [CrossRef] [PubMed]

12. Wang, R.; Reddy, P.H. Role of glutamate and NMDA receptors in Alzheimer's disease. J. Alzheimers Dis. 2017, 57 (Suppl. 4), 1041-1048. [CrossRef] [PubMed]

13. Billard, J.M. D-serine signalling as a prominent determinant of neuronal-glial dialogue in the healthy and diseased brain. J. Cell. Mol. Med. 2008, 12, 1872-1884. [CrossRef] [PubMed]

14. Sasabe, J.; Miyoshi, Y.; Suzuki, M.; Mita, M.; Konno, R.; Matsuoka, M.; Hamase, K.; Aiso, S. D-amino acid oxidase controls motoneuron degeneration through D-serine. Proc. Natl. Acad. Sci. USA 2012, 109, 627-632. [CrossRef] [PubMed]

15. Nuechterlein, K.H.; Subotnik, K.L.; Green, M.F.; Ventura, J.; Asarnow, R.F.; Gitlin, M.J.; Yee, C.M.; Gretchen-Doorly, D.; Mintz, J. Neurocognitive predictors of work outcome in recent-onset schizophrenia. Schizophr. Bull. 2011, 37, 33-40. [CrossRef] [PubMed]

16. Fujita, Y.; Ishima, T.; Hashimoto, K. Supplementation with D-serine prevents the onset of cognitive deficits in adult offspring after maternal immune activation. Sci. Rep. 2016, 6, 37261. [CrossRef] [PubMed]

17. Olferd, E.; Cross, B.; McWillian, D.; McWillian, A. Guidelines for the Use of Animal in Neuroscience Research; Canadian Council on Care (CCAC), Bradda Printing Services Inc.: Ottawa, ON, Canada, 1997; pp. 163-165.

18. Van Praag, H.; Shubert, T.; Zhao, C.; Gage, F.H. Exercise enhances learning and hippocampal neurogenesis in aged mice. J. Neurosci. 2005, 25 (Suppl. 38), 8680-8685. [CrossRef] [PubMed]

19. Almaguer-Melian, W.; Cruz-Aguado, R.; Riva, C.L.; Kendrick, K.M.; Frey, J.U.; Bergado, J. Effect of LTP-reinforcing paradigms on neurotransmitter release in the dentate gyrus of young and aged rats. Biochem. Biophys. Res. Commun. 2005, 327, 877-883. [CrossRef] [PubMed]

20. Tombaugh, G.C.; Rowe, W.B.; Chow, A.R.; Michael, T.H.; Rose, G.M. Theta-frequency synaptic potentiation in CA1 in vitro distinguishes cognitively impaired from unimpaired aged Fischer 344 rats. J. Neurosci. 2002, 22, 9932-9940. [CrossRef] [PubMed]

21. Rowe, W.B.; Spreekmeester, E.; Meaney, M.J.; Quirion, R.; Rochford, J. Reactivity to novelty in cognitively-impaired and cognitively unimpaired aged rats and young rats. Neuroscience 1998, 83, 669-680. [CrossRef]

22. Tietze, F. Enzymic method for quantitative determination of nanogram amounts of total and oxidized glutathione: Applications to mammalian blood and other tissues. Anal. Biochem. 1969, 27, 502-522. [CrossRef]

23. Buege, J.A.; Aust, S.D. Microsomal lipid peroxidation. Methods Enzymol. 1978, 52, 302-310. [PubMed]

24. Lucas, K.K.; Dennis, E.A. Distinguishing phospholipase A2 types in biological samples by employing group-specific assays in the presence of inhibitors. Prostag. Other Lipid Mediat. 2005, 77, 235-248. [CrossRef] [PubMed] 
25. Shukitt-Hale, B.; Casadesus, G.; Cantuti-Castelvetri, I.; Joseph, J.A. Effect of age on object exploration, habituation, and response to spatial and nonspatial change. Behav. Neurosci. 2001, 115, 1059-1064. [CrossRef] [PubMed]

26. Johnson, W.; Wilson-Delfosse, A.L.; Mieyal, J.J. Dysregulation of Glutathione Homeostasis in Neurodegenerative Diseases. Nutrients 2012, 4, 1399-1440. [CrossRef] [PubMed]

27. Allam, F.; Dao, T.; Gaurav, C.; Bohar, R.; Farzan, J. Grape Powder supplementation prevents oxidative stress-induced anxiety-like behaviour, memory impairment and high blood pressure in rats. J. Nutr. 2013, 8, 835-841. [CrossRef] [PubMed]

28. Blanco-Lezcano, L.; Jimenez-Martin, J.; Díaz-Hung, M.L.; Alberti-Amador, E.; Wong-Guerra, M.; González-Fraguela, M.E.; Estupiñán-Díaz, B.; Serrano-Sánchez, T.; Francis-Turner, L.; Delgado-Ocaña, S.; et al. Motor dysfunction and alterations in glutathione concentration, cholinesterase activity, and BDNF expression in substantia nigra pars compacta in rats with pedunculopontine lesion. Neuroscience 2017, 348, 83-97. [CrossRef] [PubMed]

29. Mattson, M.P. ER calcium and Alzheimer's disease: In a state of flux. Sci. Signal. 2010, 3, pe10. [CrossRef] [PubMed]

30. Rao, J.S.; Kellom, M.; Reese, E.A.; Rapoport, S.I.; Kim, H.-W. Dysregulated glutamate and dopamine transporters in postmortem frontal cortex from bipolar and schizophrenic patients. J. Affect. Disord. 2012, 136, 63-71. [CrossRef] [PubMed]

31. Chalimoniuk, M.; Stolecka, A.; Zieminska, E.; Stepien, A.; Langfort, J.; Strosznaider, J.B. Involvement of multiple protein kinases in cPLA2 phosphorylation, arachidonic acid release, and cell death in vivo and in vitro models of 1-methyl-4-phenylpyridinium-induced parkinsonism-The possible key role of PKG. J. Neurochem. 2009, 110, 307-317. [CrossRef] [PubMed]

32. Last, V.; Williams, A.; Werling, D. Inhibition of cytosolic phospholipase A2 prevents prion peptide-induced neuronal damage and co-localisation with beta iii tubulin. BMC Neurosci. 2012, 13, 106. [CrossRef] [PubMed]

33. Beckhauser, T.F.; Francis-Oliveira, J.; De Pasquale, R. Reactive Oxygen Species: Physiological and Physiopathological Effects on Synaptic Plasticity. J. Exp. Neurosci. 2016, 10 (Suppl. 1), 23-48. [CrossRef] [PubMed]

34. Serrano, F.; Chang, A.; Hernandez, C.; Pautler, R.G.; Sweatt, J.D.; Klann, E. NADPH oxidase mediates beta-amyloid peptide-induced activation of ERK in hippocampal organotypic cultures. Mol. Brain 2009, 2, 31. [CrossRef] [PubMed]

35. Adibhatla, R.M.; Hatcher, J.F.; Dempsey, R.J. Phospholipase A2, hydroxyl radicals, and lipid peroxidation in transient cerebral ischemia. ARS 2003, 5 (Suppl. 5), 647-654. [CrossRef] [PubMed]

36. Cocco, T.; Di Paola, M.; Papa, S.; Lorusso, M. Arachidonic acid interaction with the mitochondrial electron transport chain promotes reactive oxygen species generation. Free Radic. Biol. Med. 1999, 27 (Suppl. 1-2), 1-2). [CrossRef]

37. Jiang, R.; Chen, S.; Shen, Y.; Wu, J.; Chen, S.; Wang, A.; Wu, S.; Zhao, X. Higher Levels of Lipoprotein Associated Phospholipase A2 is associated with Increased Prevalence of Cognitive Impairment: The APAC Study. Sci. Rep. 2016, 6, 33073. [CrossRef] [PubMed]

38. Shelat, P.B.; Chalimoniuk, M.; Wang, J.H.; Strosznajder, J.B.; Lee, J.C.; Sun, A.Y.; Simonyi, A.; Sun, G.Y. Amyloid beta peptide and NMDA induce ROS from NADPH oxidase and AA release from cytosolic phospholipase A2 in cortical neurons. J. Neurochem. 2008, 106 (Suppl. 1), 45-55. [CrossRef] [PubMed]

39. Snyder, E.M.; Nong, Y.; Almeida, C.G.; Paul, S.; Moran, T.; Choi, E.Y.; Nairn, A.C.; Salter, M.W.; Lombroso, P.J.; Gouras, G.K.; et al. Regulation of NMDA receptor trafficking by amyloid-beta. Nat. Neurosci. 2005, 8, 1051-1058. [CrossRef] [PubMed]

40. Calon, F.; Lim, G.P.; Morihara, T.; Yang, F.; Ubeda, O.; Salem, N., Jr.; Frautschy, S.A.; Cole, G.M. Dietary n-3 polyunsaturated fatty acid depletion activates caspases and decreases NMDA receptors in the brain of a transgenic mouse model of Alzheimer's disease. Eur. J. Neurosci. 2005, 22, 617-626. [CrossRef] [PubMed]

41. Bergado, A.; Lucas, M.; Richter-Levin, G. Emotional tagging-A simple hypothesis in a complex reality. Prog. Neurobiol. 2011, 94 (Suppl. 1), 64-76. [CrossRef] [PubMed]

42. Baxter, P.S.; Bell, K.F.S.; Hasel, P.; Kaindl, A.M.; Fricker, M.; Thomson, D.; Cregan, S.P.; Gillingwater, T.H.; Hardingham, G.H. Synaptic NMDA receptor activity is coupled to the transcriptional control of the glutathione system. Nat. Commun. 2015, 6, 6761. [CrossRef] [PubMed] 
43. Foster, C.F. Dissecting the age-related decline on spatial learning and memory tasks in rodent models: $\mathrm{N}$-methyl-D-aspartate receptors and voltage-dependent $\mathrm{Ca}^{2+}$ channels in senescent synaptic plasticity. Prog. Neurobiol. 2012, 96 (Suppl. 3), 283-303. [CrossRef] [PubMed]

44. Liu, C.; Liu, Y.; Yang, Z. Myocardial infarction induces cognitive impairment by increasing the production of hydrogen peroxide in adult rat hippocampus. Neurosci. Lett. 2014, 560, 112-116. [CrossRef] [PubMed]

45. Murray, J.D.; Antigenic, A.; Gancsos, M.; Ichinose, M.; Corlett, P.R.; Krystal, J.H.; Wang, X.J. Linking microcircuit dysfunction to cognitive impairment: Effects of disinhibition associated with schizophrenia in a cortical working memory model. Cereb. Cortex 2014, 24, 859-872. [CrossRef] [PubMed]

46. Abe, T.; Suzuki, M.; Sasabe, J.; Takahashi, S.; Unekawa, M.; Mashima, K.; Iizumi, T.; Hamase, K.; Konno, R.; Aiso, S.; et al. Cellular origin and regulation of $\mathrm{D}$ - and $\mathrm{L}$ serine in in vitro and in vivo models of cerebral ischemia. J. Cereb. Blood Flow Metab. 2014, 34, 1928-1935. [CrossRef] [PubMed]

47. Balu, D.T.; Coyle, J.T. The NMDA receptor 'glycine modulatory site' in schizophrenia: D-serine, glycine, and beyond. Curr. Opin. Pharmacol. 2015, 20, 109-115. [CrossRef] [PubMed]

48. Benneyworth, M.A.; Li, Y.; Basu, A.C.; Bolshakov, V.Y.; Coyle, J.T. Cell selective conditional null mutations of serine racemase demonstrate a predominate localization in cortical glutamatergic neurons. Cell. Mol. Neurobiol. 2012, 32, 613-624. [CrossRef] [PubMed]

49. Suzuki, M.; Imanishi, N.; Mita, M.; Hamase, K.; Aiso, S.; Sasabe, J. Heterogeneity of D-Serine Distribution in the Human Central Nervous System. ASN Neuro 2017, 1-10. [CrossRef] [PubMed]

50. Wolosker, H.; Balu, D.T.; Coyle, J.T. The Rise and Fall of the d-Serine-Mediated Gliotransmission Hypothesis. Trends Neurosc. 2016, 39, 712-721. [CrossRef] [PubMed]

51. Vanoni, M.A.; Cosma, A.; Mazzeo, D.; Mattevi, A.; Todone, F.; Curti, B. Limited proteolysis and X-ray crystallography reveal the origin of substrate specificity and of the rate-limiting product release during oxidation of D-amino acids catalyzed by mammalian D-amino acid oxidase. Biochemistry 1997, 36, 5624-5632. [CrossRef] [PubMed]

52. Sasabe, J.; Chiba, T.; Yamada, M.; Okamoto, K.; Nishimoto, I.; Matsuoka, M.; Aiso, S. D-Serine is a key determinant of glutamate toxicity in amyotrophic lateral sclerosis. EMBO J. 2007, 26, 4149-4159. [CrossRef] [PubMed]

53. Miladinovic, T.; Nashed, M.G.; Singh, G. Overview of Glutamatergic Dysregulation in Central Pathologies. Biomolecules 2015, 5, 3112-3141. [CrossRef] [PubMed]

54. Yang, S.; Qiao, H.; Wen, L.; Zhou, W.; Zhang, Y. D-serine enhances impaired long-term potentiation in CA1 subfield of hippocampal slices from aged senescence-accelerated mouse prone/8. Neurosci. Lett. 2005, 379, 7-12. [CrossRef] [PubMed]

(C) 2018 by the authors. Licensee MDPI, Basel, Switzerland. This article is an open access article distributed under the terms and conditions of the Creative Commons Attribution (CC BY) license (http://creativecommons.org/licenses/by/4.0/). 